\title{
Reconsidering fetal pain
}

\author{
Stuart WG Derbyshire 다, ${ }^{1}$ John C Bockmann²
}

${ }^{1}$ Psychology and NUS Clinical Imaging Research Centre, National University of Singapore, Singapore ${ }^{2}$ Conner Troop Medical Clinic, Fort Drum, New York, USA

Correspondence to Dr Stuart WG Derbyshire, Psychology, National University of Singapore, Singapore; psydswg@nus.edu.sg

Received 11 July 2019 Revised 5 October 2019 Accepted 17 October 2019 Published Online First 14 November 2019

\section{Check for updates}

(C) Author(s) (or their employer(s)) 2020. No commercial re-use. See rights and permissions. Published by BMJ.

To cite: Derbyshire SWG Bockmann JC. J Med Ethics 2020;46:3-6.

\section{ABSTRACT}

Fetal pain has long been a contentious issue, in large part because fetal pain is often cited as a reason to restrict access to termination of pregnancy or abortion. We have divergent views regarding the morality of abortion, but have come together to address the evidence for fetal pain. Most reports on the possibility of fetal pain have focused on developmental neuroscience. Reports often suggest that the cortex and intact thalamocortical tracts are necessary for pain experience. Given that the cortex only becomes functional and the tracts only develop after 24 weeks, many reports rule out fetal pain until the final trimester. Here, more recent evidence calling into question the necessity of the cortex for pain and demonstrating functional thalamic connectivity into the subplate is used to argue that the neuroscience cannot definitively rule out fetal pain before 24 weeks. We consider the possibility that the mere experience of pain, without the capacity for self reflection, is morally significant. We believe that fetal pain does not have to be equivalent to a mature adult human experience to matter morally, and so fetal pain might be considered as part of a humane approach to abortion.

\section{INTRODUCTION}

In 1983, President Ronald Reagan wrote an article in Human Life Review that (to our knowledge) first directly raised the possibility that the fetus can "respond to pain". ${ }^{1}$ Subsequently, the possibility of fetal pain was raised in a review in the New England Journal of Medicine, ${ }^{2}$ an accompanying editorial, ${ }^{3}$ and a clinical trial examining the use of analgesia and anaesthesia for neonatal surgery. ${ }^{4}$ More recently, debate about fetal pain has become embroiled in discussions about abortion, and the possibility of fetal pain has been cited in several US laws aiming to restrict access to abortion. ${ }^{5}$

The two authors of this paper have very different views on the morality of abortion. One of us believes that abortion is necessary for women's health and autonomy, while the other believes that abortion violates the ethical principle of non-maleficence and ought to be restricted and discouraged. Regardless of our stark differences on this question, we both believe that our moral views on abortion should not interfere with discussion of whether fetal pain is possible and whether the science of fetal development can rule out the possibility of fetal pain. We also agree that if fetal pain is likely then that has ethical and clinical significance independent of any views on the morality of abortion per se. That said, it is also clear to us that the issue of fetal pain has ethical significance because of abortion practices and not because of other surgical or therapeutic fetal procedures.

Worldwide, it is estimated that there are 56 million induced abortions each year, corresponding to $25 \%$ of all pregnancies. ${ }^{6}$ In high income countries with relatively liberal abortion laws, over $90 \%$ of all abortions take place before 13 weeks' gestation. ${ }^{7}$ We argue that abortions before 13 weeks' gestation do not involve any meaningful likelihood of pain for the fetus. Abortions after 13 weeks are typically either medical or surgical. ${ }^{8}$ Medical abortions involve a drug or drug combination provided to the patient to induce abortion. Today the drug combination is commonly mifepristone and misoprostol that do not kill the fetus. Fetal death follows either direct feticide (an injection of potassium chloride directly into the fetal heart or an injection of digoxin directly into the fetus or intra-amniotically) or the trauma of labour. The most common surgical technique is dilatation and evacuation (D\&E). In a D\&E, the cervix is dilated, the amniotic fluid drained, and the fetus is removed in pieces via several surgical manoeuvres using grasping forceps. Again fetal death follows either direct feticide performed before the D\&E or the trauma of the D\&E results in the death of the fetus. We consider the possibility of fetal pain during these two procedures post-13 weeks' gestation. We will begin by presenting our reasoning behind our view that the issue of fetal pain has little ethical significance during therapeutic fetal surgical procedures. From there we discuss the neuroscientific and psychological evidence for and against the possibility of fetal pain before examining the ethical implications of fetal pain.

\section{Therapeutic fetal intervention}

There have been impressive developments in therapeutic fetal intervention since the first intraperitoneal blood transfusion to a fetus in 1963 and the first successful human fetal surgery in $1981 .^{59}$ To date, fetal surgery has been successfully implemented for repair of various defects (myelomeningocele, obstructive uropathy, congenital diaphragmatic hernia, congenital heart defects, congenital pulmonary airway malformation), removal of various tumours (chorioangioma, sacrococcygeal teratoma), as well as for specific procedures including twin-to-twin transfusion syndrome and EXIT (ex utero intrapartum treatment) procedures. ${ }^{10} 11$ The development of invasive surgical procedures to treat the fetus has been accompanied by specialist development of fetal and maternal analgesia and anaesthesia to support those procedures. ${ }^{12-14}$

Up until the late 1980s, surgical procedures with neonates were mostly performed without analgesia or anaesthesia largely because of safety concerns and because it was assumed the neonate was not neurologically sophisticated enough to experience pain. A series of clinical trials clearly demonstrated that anaesthesia and analgesia are safe for neonates and provide for improved postoperative outcome. ${ }^{4}$ These important findings led to calls for clinical practice with neonates to be changed and operations with neonates are no longer performed without an anaesthetic and analgesic regimen. 
Similar randomised trials with fetal patients might be suggested as an obvious means of demonstrating whether safety concerns can also be minimised for fetal surgery. The rarity and idiosyncratic nature of in utero surgical procedures, however, means that randomised trials are impractical and might be deemed unethical. Consequently, fetal anaesthesia has been developed based on clinical expertise and observation. Most procedures include a general anaesthetic transferred across the placenta often supplemented by an opioid agent and a paralytic agent. ${ }^{10}$ Some concerns have been raised that these agents may have harmful effects on cells, may have negative effects on brain development, or may critically interfere with the fetal cardiovascular system. ${ }^{15-17}$ To our knowledge, however, all clinicians or surgeons working with fetal patients advocate the use of fetal anaesthesia and analgesia as standard practice. While further studies might be welcome to address the optimal procedures necessary to improve outcomes, there is consensus that the use of fetal anaesthesia and analgesia improves maternal and fetal cardiovascular stability, provides the necessary immobility of the fetus and prevents a dangerous fetal physiologic reaction or "stress response" to the surgery. ${ }^{12} 14$

Currently, therefore, we are not aware of any procedures where invasive fetal intervention proceeds without anaesthesia or analgesia, except for abortion. The lack of an evidence base for fetal anaesthesia and analgesia, however, and the need for clinicians to use their professional judgement, means it is theoretically possible that a surgeon or medical team will judge analgesia or anaesthesia as not in the best interest of their fetal patient. In such a (hypothetical) case, the fetus will feel pain if fetal pain is possible. For therapeutic procedures, such pain can be ethically offset. The principle of non-maleficence implies we should first of all do no harm, ${ }^{18}$ but pain can be acceptable if the inflicted pain is part of a good faith effort to save or improve the life of the patient. This is the case with therapeutic fetal surgery, and with other invasive procedures, such as blood transfusions and the use of instruments for delivery, aimed at supporting fetal or infant life. Therefore, while surgeons and medical teams might be minded to consider fetal pain (and all the evidence suggests they clearly are), the possibility of fetal pain is not a reason to change current medical practice surrounding fetal surgery or other invasive procedures designed to preserve or enhance fetal life.

Abortion is different for at least two reasons. First, abortion may prevent future suffering that results from being born in a state of painful physical disability, but an abortion is not designed to preserve or enhance ongoing fetal life. In the cases where little or no disability is expected, there is little or no future benefit to the fetus from the pain they might experience. Second, while all the evidence suggests that surgeons performing therapeutic fetal interventions routinely consider pain relief for the fetus, surgeons performing abortions have their focus on the pregnant woman as their patient. ${ }^{19}$ Consequently they more rarely consider fetal pain relief during the preparation and execution of abortion. Whether or not the fetus feels pain, therefore, is relevant to current medical practice surrounding abortion and could motivate changes in practice.

\section{Neuroscientific arguments for fetal pain}

The most common approach to the possibility of fetal pain is the attempt to align the developing neurology of the fetus to what is considered necessary for pain experience. ${ }^{20} 21$ Often it is stated that there is a consensus that pain is not possible before development of the cortex, and before the periphery is connected to the cortex through the spinal cord and thalamus.
Those developments are broadly not apparent before 24 weeks' gestation and so many medical bodies and press reports state that pain is not possible before 24 weeks' gestation, which is the point at which most abortions cease to be legal in most parts of the world. ${ }^{5}$

Arguably, there never was a consensus that fetal pain is not possible before 24 weeks. Many papers discussing fetal pain have speculated a lower limit for fetal pain under 20 weeks' gestation. ${ }^{22-25}$ We note in passing that vote counting and consensus is perhaps not the best way to decide scientific disputes. Regardless of whether there ever was a consensus, however, it is now clear that the consensus is no longer tenable.

Several papers have now been published suggesting that the necessity of the cortex for pain experience may have been overstated. ${ }^{26-29}$ One study has, for example, demonstrated continued pain experience in a patient with extensive damage to cortical regions generally believed to be necessary for pain experience. ${ }^{28}$ A further study has demonstrated activation of areas generally thought to generate pain in subjects congenitally insensitive to pain but receiving noxious stimuli. ${ }^{29}$ While certainly not definitive, those two studies appear to neatly dissociate pain experience from the cortex.

In addition, previous proponents of fetal pain speculated that neural activity in the subplate might support fetal pain experience. ${ }^{23}$ At 12 weeks' gestation there are the first projections from the thalamus into the cortical subplate. ${ }^{30} 31$ The subplate is a transient developmental structure that forms underneath the cortical plate proper. Neurons destined for the cortical plate first migrate into the subplate where they wait until the cortical plate above is sufficiently mature and then the neurons migrate to their mature position in the cortex. The subplate then gradually withers away and becomes white matter. Recent work with ferrets has demonstrated that auditory stimuli trigger neural activity in the subplate that is topographically highly similar to the activity observed in the more mature auditory cortex. ${ }^{32}$ Moreover, the neural activity in the subplate is tonotopically organised and the connectivity and activity of at least some subplate neurons are preserved into adulthood. That is, the thalamocortical projections that are largely considered necessary for mature sensory function are at least in part preserved from the subplate into the cortical plate. Given that the development of all sensory systems follow a similar developmental trajectory and all involve the subplate, it is likely that a bodily mapping of sensory subplate neurons supporting a sensory homunculus will occur, similar to the tonotopic mapping of the subplate supporting auditory processing. Future studies, however, may examine that possibility directly.

In summary, current neuroscientific evidence undermines the necessity of the cortex for pain experience. Even if the cortex is deemed necessary for pain experience, there is now good evidence that thalamic projections into the subplate, which emerge around 12 weeks' gestation, are functional and equivalent to thalamocortical projections that emerge around 24 weeks' gestation. Thus, current neuroscientific evidence supports the possibility of fetal pain before the "consensus" cutoff of 24 weeks.

A difficulty that faces everyone trying to adjudicate on the issue of fetal pain from neuroscientific findings is the intense uncertainty of exactly how the neural activity of the brain translates into the subjective experience of pain. ${ }^{33}$ The association of coherent neural activity in brain stem circuits with phenomenal consciousness, such as has been suggested by Merker, ${ }^{34}$ has at least a similar validity to the association of coherent neural activity in the cortex with phenomenal consciousness. 
Coherence and location, in and of themselves, do not provide an explanation for how the underlying nerve impulses, which are inherently unconscious biophysical events, are translated into phenomenological components of experience.

\section{Psychological arguments for fetal pain}

A different approach to unravelling whether a fetus feels pain is to focus more closely on what we mean by "pain". Many people take the International Association for the Study of Pain definition as their starting point, which states that pain is "an unpleasant sensory and emotional experience associated with actual or potential tissue damage, or described in terms of such damage... pain is always subjective. Each individual learns the application of the word through experiences related to injury in early life. ${ }^{35}$ That definition is often interpreted as meaning that pain is not just phenomenological but also reflective. ${ }^{36-39}$ As others have pointed out, such a demanding definition of pain restricts pain almost exclusively to fairly mature human beings. ${ }^{36}{ }^{37}$ To ease that restriction it might be worthwhile to consider a less sophisticated definition, which focuses less on subjective reflection (knowing that I am in pain) and more on the immediate and unreflective feel of pain (being in pain).

The possibility of an immediate and unreflective experience of pain gels more clearly with the possibility of pain being based in subcortical, rather than cortical, activity as others have suggested. ${ }^{23} 3438$ An immediate and unreflective, or core, pain experience, however, does lack epistemological clarity as to the exact nature or content of the pain experience. ${ }^{39}$ Sense experiences do not occur in isolation and nor are they dissected into immediate features and components that are independent of, or completely walled off from, higher-order consciousness. While we can identify separate features (colours, edges, luminance, and so forth) those separate features are not fragmented from the unity of our conscious self. When we experience red, for example, we experience ourselves as the subject seeing red with the knowledge that we are seeing a particular colour, an experience encompassing memory, understanding, and so on. The red is inescapably about something that is more than any immediate and bounded experience. Red essentially refers to, or is constituent to, a part of a greater scene (a painting, a sunset, a traffic warning, and so on). Red might conjure up an inner state of consciousness relating to fear or concern, desire or excitement, and will afford certain actions and so on. It is difficult for us to withdraw into a fundamental, or "pure" experience of red because we always experience red from our point of view, from the perspective of our lived and ongoing life.

When we experience pain, we experience ourselves as the bearer of pain with the knowledge that we are in pain, an experience encompassing memory, understanding, and so on. The pain is inescapably about something that is more than any immediate and bounded experience. Pain essentially refers to, or is constituent to, a part of the body (an arm, leg, head, and so on). Pain often refers to a stimulus with degrees of threat (a thorn vs a spear or indigestion vs a heart attack), and pain conjures up an inner state of consciousness relating to fear, concern, regret, necessary action and so on. ${ }^{40}$ We do not propose that the fetus experiences that; such an all-encompassing conscious experience likely does depend on widespread cortical activity, as discussed elsewhere. ${ }^{41}$ Instead, we propose that the fetus experiences a pain that just is and it is because it is, there is no further comprehension of the experience, only an immediate apprehension. The fetus experiences something that is inherent to a certain level of biological activity, and which emerges at an unknown time often speculated to be after 12 weeks' gestation. Our position is quite similar to that of others who have argued that animals might not feel pain at all or feel something that is direct and bodily and not connected to any reflection such that the animal might regard the sensation as unpleasant or, indeed, regard the sensation as anything at all. ${ }^{42} 43$ It can be argued that such a pain lacks moral relevance, but we view that position with some suspicion. We may doubt whether the fetus (or an animal) ever feels anything akin to pain, but acting as if we have certainty flirts with a moral recklessness that we are motivated to avoid.

\section{The moral implications of fetal pain}

Therapeutic fetal surgery poses certain ethical challenges as discussed elsewhere, ${ }^{44}$ but those challenges are not obviously altered or added to by the possibility of fetal pain. Fetal pain does, however, pose a challenge to abortion providers. Concerns about what the fetus might experience or feel have increased, and women considering an abortion express concern about the welfare of the fetus. ${ }^{19} 4546$ Given the evidence that the fetus might be able to experience something like pain during later abortions, it seems reasonable that the clinical team and the pregnant woman are encouraged to consider fetal analgesia. For procedures that involve direct feticide, the possibility of fetal pain is limited to the injection period. The injection provides a nociceptive stimulus that previous studies have associated with a stress response. ${ }^{46}$ In the absence of feticide, the trauma of premature birth for medical abortion might result in mechanical pressure that will reach noxious levels, but that pressure is not likely to exceed that produced in a normal delivery at full term. A D\&E procedure will deliver repeated nociceptive events that may involve fetal pain before fetal death.

We disagree as to exactly how the "encouragement" to consider fetal analgesia might be implemented for the above procedures. One of us essentially believes that the momentary interests of the fetus as it leaves this life can be accommodated as part of a humane approach to abortion. The clinical team and the pregnant woman can consider whether fetal analgesia makes sense based on the clinical requirements for the abortion, the age of the fetus, and the conscience of the parties involved. The other essentially believes that abortion is inherently violent and may subject the fetus to unnecessary pain and distress after the first trimester. Fetal analgesia and anaesthesia should thus be standard for abortions in the second trimester, especially after 18 weeks when there is good evidence for a functional connection from the periphery and into the brain. ${ }^{46}$

\section{FINAL THOUGHTS}

The precise nature of fetal pain experience remains unknown and will, perhaps, remain forever unknowable. None of us can return to a state of conscious "innocence" to report on existence before our self-reflective lives. Nevertheless, we remain hopeful that other philosophers, psychologists, clinicians and neuroscientists might cast some light into that darkness.

The major practical outcome of this review, however, is that both authors agree that it is reasonable to consider some form of fetal analgesia during later abortions. It might be argued that given our inability to access the fetal mind it is unduly hasty, and risky, to introduce a further clinical procedure during abortion. New procedures could result in new risks for the pregnant woman, and, for all we know, providing the fetus with analgesia might be painfulit might burn as it courses through the fetus. We are certainly minded not to introduce unnecessary risks and procedures, but we believe that expert clinical teams, and pregnant women, can at least consider and balance those risks. The possibility of the fetus experiencing more pain through efforts to abolish pain seems 
highly unlikely, even fanciful. Fetal analgesia results in a fetus with lowered blood pressure and reduced heart rate, and a fetus that is still and appears quiescent and calm. ${ }^{10-14}$ It would be a perverse turn of nature for that condition of quiescence to be accompanied by enhanced rather than reduced pain. Overall, the evidence, and a balanced reading of that evidence, points towards an immediate and unreflective pain experience mediated by the developing function of the nervous system from as early as 12 weeks. That moment is not categorical, fetal development is continuous and not an event, and we recognise that some evidence points towards an immediate and unreflective pain not being possible until later. ${ }^{47}$ Nevertheless, we no longer view fetal pain (as a core, immediate, sensation) in a gestational window of 12-24 weeks as impossible based on the neuroscience.

The two authors came together to write this paper through a shared sense that the neuroscientific data, especially more recent data, could not support a categorical rejection of fetal pain. We also both grew increasingly dissatisfied with the rejection of fetal pain based on a definition of pain that is useful when dealing with patients presenting with pain, but not appropriate to considering the kind of pain a fetus might plausibly experience. We hope that this short report can provide the basis for further consideration of how neuroscientific findings relate to phenomenological experience, further discussion of the nature of phenomenological experience in human adults and those with lesser conceptual capacity, and point towards a reasoned approach to pain relief even when the pain experienced cannot be explicitly expressed or measured. In short, our goal was to generate a better conversation on the possibility of fetal pain and the implications of that possibility.

Twitter Stuart WG Derbyshire @painfulgains and John C Bockmann @BockmannJohn

Contributors SWGD and JCB both conceived the content and discussed the material over several years. SWGD wrote the first draft and JCB provided edits and further input.

Funding The authors have not declared a specific grant for this research from any funding agency in the public, commercial or not-for-profit sectors.

Competing interests None declared.

Patient consent for publication Not required.

Provenance and peer review Not commissioned; externally peer reviewed.

\section{ORCID iD}

Stuart WG Derbyshire http://orcid.org/0000-0002-2766-3424

\section{REFERENCES}

1 Reagan R. Abortion and the conscience of the nation. The Human Life Review 1983.

2 Anand KJS, Hickey PR. Pain and its effects in the human neonate and fetus. N Eng/ J Med 1987;317(21):1321-9.

3 Rogers MC. Do the right thing. N Eng/ J Med 1992;326(1):55-6.

4 Anand KJS, Sippel WG, Aynsley-Green A. Randomised trial of fentanyl anaesthesia in preterm babies undergoing surgery: effects on the stress response. Lancet 1987;1:243-8.

5 Derbyshire SWG. Fetal pain and the law: abortion laws and their relationship to ideas about pain and fetal pain. In: The Routledge Handbook of Philosophy of Pain. J Corns, Ed. Taylor \& Francis Books Oxford, 2017.

6 Guttmacher Institute. Fact sheet: induced abortion worldwide. New York, NY, 2018 Available: https://www.guttmacher.org/fact-sheet/induced-abortion-worldwide

7 Popinchalk A, Sedgh G. Trends in the method and gestational age of abortion in highincome countries. BMJ Sex Reprod Health 2019;45(2):95-103.

8 Lohr PA, Hayes JL, Gemzell-Danielsson K, et al. Surgical versus medical methods for second trimester induced abortion. Cochrane Database Syst Rev 2008;137(3).

9 Liley AW. Intrauterine transfusion of foetus in haemolytic disease. BMJ 1963;2(5365):1107-9.

10 Harrison MR, Golbus MS, Filly RA, et al. Fetal surgery for congenital hydronephrosis. N Engl J Med 1982;306(10):591-3.
11 Deprest J, Hodges R, Gratacos E, et al. Invasive fetal therapy. In: Creasy and Resnik's Maternal-Fetal Medicine: Principles and Practice. 7th ed. Creasy RK, Resnik R, lams $J D$, Lockwood CJ, Moore TR, Greene MF (Eds). Philadelphia, PA: Elsevier Saunders, 2014: 516-57.

12 Rollins MD, Rosen MA. Anesthesia for fetal surgery and other intrauterine procedures. In: Chestnut's Obstetric Anesthesia Principles and Practice, ed 5. Chestnut DH (Ed. Philadelphia PA: Elsevier Saunders, 2014: 128-47.

13 Fink RJ, Allen TK, Habib AS. Remifentanil for fetal immobilization and analgesia during the ex utero intrapartum treatment procedure under combined spinal-epidural anaesthesia †. Br J Anaesth 2011;106(6):851-5.

14 van de Velde M, De Buck F. Fetal and maternal analgesia/anesthesia for fetal procedures. Fetal Diagn Ther 2012:31(4):201-9.

15 Stephanova E, Topouzova-Hristova T, Hazarosova R, et al. Halothane-induced alterations in cellular structure and proliferation of A549 cells. Tissue and Cell 2008:40(6):397-404.10.1016/j.tice.2008.04.001

16 Stratmann G. Neurotoxicity of anesthetic drugs in the developing brain. Anesth Analg 2011:113(5):1170-9.10.1213/ANE.0b013e318232066c

17 Okutomi T, Whittington RA, Stein DJ, et al. Comparison of the effects of sevoflurane and isoflurane anesthesia on the maternal-fetal unit in sheep. J Anesth 2009;23(3):392-8.

18 Brennan F, Carr DB, Cousins M. Pain management: a fundamental human right. Anesth Analg 2007;105(1):205-21.

19 Furedi A. The moral case for abortion. Palgrave Macmillan, 2016

20 Lee SJ, Ralston HJP, Drey EA, et al. Fetal pain: a systematic multidisciplinary review of the evidence. JAMA 2005;294(8):947-54.

21 Royal College of Obstetricians and Gynaecologists (RCOG). Fetal awareness review of research and recommendations for practice: report of a working party. London: RCOG Press, 2010.

22 Brusseau R, Myers L. Developing consciousness: fetal anesthesia and analgesia. Seminars in Anesthesia, Perioperative Medicine and Pain 2006;25(4):189-95.

23 Lowery CL, Hardman MP, Manning N, et al. Neurodevelopmental changes of fetal pain. Semin Perinatol 2007;31(5):275-82.

24 Van Scheltema PNA, Bakker SEM, Vandenbussche F, et al. Fetal pain. Fetal Matern Med Rev 2008;19(4):311-24.

25 Devor M, Rappaport I, Rappaport ZH. Does the Golem feel pain? Moral instincts and ethical dilemmas concerning suffering and the brain. Pain Pract 2015;15(6):497-508.

26 Iannetti GD, Mouraux A. From the neuromatrix to the pain matrix (and back). Exp Brain Res 2010;205(1):1-12.

27 Mouraux A, Diukova A, Lee MC, et al. A multisensory investigation of the functional significance of the "pain matrix". Neuroimage 2011;54(3):2237-49.

28 Feinstein JS, Khalsa SS, Salomons TV, et al. Preserved emotional awareness of pain in a patient with extensive bilateral damage to the insula, anterior cingulate, and amygdala. Brain Struct Funct 2016;221(3):1499-511.

29 Salomons TV, lannetti GD, Liang M, et al. The "pain matrix" in pain-free individuals. JAMA Neurol 2016;73(6):755.

30 Kostović I, Judaš M. The development of the subplate and thalamocortical connections in the human foetal brain. Acta Paediatr 2010;99(8):1119-27.

31 Ulfig N, Neudorfer F, Bohl J. Transient structures of the human fetal brain: subplate, thalamic reticular complex, ganglionic eminence. Histol Histopathol 2000;15:771-90.

32 Wess JM, Isaiah A, Watkins PV, et al. Subplate neurons are the first cortical neurons to respond to sensory stimuli. Proc Natl Acad Sci U S A 2017;114(47):12602-7.

33 Chalmers DJ. Facing up to the problem of consciousness. J Conscious Stud 1995;2:200-19.

34 Merker B. Consciousness without a cerebral cortex: a challenge for neuroscience and medicine. Behav Brain Sci 2007;30(1):63-81.

35 Merskey H. The definition of pain. Eur Psych 1991;6:153-9.

36 Anand KJS, Craig KD. New perspectives on the definition of pain. Pain 1996;67:3-6.

37 Derbyshire SWG, Raja A. On the development of painful experience. J Conscious Stud 2011;18:233-56.

38 Davis KD, Kucyi A, Moayedi M. The pain switch: an "ouch" detector. Pain 2015;156:2164-6.

39 Sullivan MD, Derbyshire SW. Is there a purely biological core to pain experience? Pain 2015;156(11):2119-20.

40 Tallis R. The Knowing Animal: A Philosophical Inquiry into Knowledge and Truth. Edinburgh: Edinburgh University Press, 2005.

41 Lagercrantz $\mathrm{H}$. The emergence of consciousness: science and ethics. Semin Fetal Neonatal Med 2014:19(5):300-5.

42 Harrison P. Do animals feel pain? Philosophy 1991;66(255):25-40.

43 Murray MJ, Ross G, The Society of Christian Philosophers. Neo-Cartesianism and the problem of animal suffering. Faith Philos 2006;23(2):169-90.

44 Smajdor A. Ethical challenges in fetal surgery. J Med Ethics 2011;37(2):88-91.

45 Furedi A. Issues for service providers: a response to points raised. J Med Ethics 2001;27(Supplement 2):ii28-32.

46 Giannakoulopoulos X, Glover V, Sepulveda W, et al. Fetal plasma cortisol and $\beta$-endorphin response to intrauterine needling. Lancet 1994:344(8915):77-81.

47 Tadros MA, Lim R, Hughes DI, et al. Electrical maturation of spinal neurons in the human fetus: comparison of ventral and dorsal horn. J Neurophysiol 2015;114(5):2661-71. 